\title{
Establishment of three malignant peripheral nerve sheath tumor cell lines, FU-SFT8611, 8710 and 9817: Conventional and molecular cytogenetic characterization
}

\author{
MIKIKO AOKI $^{1}$, KAZUKI NABESHIMA $^{1}$, JUN NISHIO ${ }^{1}$, MASAKO ISHIGURO $^{1}$, CHIKAKO FUJITA $^{1}$ \\ KAORI KOGA ${ }^{1}$, MAKOTO HAMASAKI ${ }^{1}$, YASUHIKO KANEKO ${ }^{2}$ and HIROSHI IWASAKI ${ }^{1}$ \\ ${ }^{1}$ Department of Pathology, Fukuoka University Faculty of Medicine, 7-45-1 Nanakuma, \\ Jonan-ku, Fukuoka 814-0180; ${ }^{2}$ Laboratory Medicine, Saitama Cancer Center, Saitama 362-0806, Japan
}

Received July 10, 2006; Accepted September 5, 2006

\begin{abstract}
Malignant peripheral nerve sheath tumor (MPNST) is a rare malignant tumor, for which only a few cultured cell lines are available to date. In the present study, we established three new MPNST cell lines, FU-SFT8611, FU-SFT8710 and FU-SFT9817, from a 40-year-old Japanese man without neurofibromatosis 1 (NF1), a 43-year-old Japanese woman with NF1, and a 61-year-old Japanese woman without NF1, respectively. These cell lines were in culture for more than 3 years in vitro, and exhibit complex karyotypes lacking a common characteristic pattern. Two of the cell lines, FUSFT8611 and FU-SFT9817, were tumorigenic in nude mice, with the resultant tumors showing an immunohistochemical phenotype similar to the original tumors. Comparative genomic hybridization analysis revealed that chromosomal imbalances were very similar between the original tumors and the established cell lines, but no consistent imbalances among the three cell lines as reported so far. As for chromosomal imbalances that have been reported to be associated with poor survival, FU-SFT8611 exhibited a gain of chromosome 17q22-qter, and FU-SFT9817 showed a loss of 17q22-qter, while gains of 17q24 and 7p15-p21 were observed in none of the cell lines. These newly established cell lines provide a valuable resource for biological and pathological investigations into new treatment regimes for MPNST.
\end{abstract}

\section{Introduction}

Malignant peripheral nerve sheath tumor (MPNST) is a rare malignant soft tissue tumor that accounts for nearly $5 \%$ of soft tissue malignancies, and approximately $50 \%$ of cases are

Correspondence to: Dr Mikiko Aoki, Department of Pathology, Fukuoka University School of Medicine, 7-45-1 Nanakuma, Jonan-ku, Fukuoka 814-0180, Japan

E-mail: mikikoss@eurus.dti.ne.jp

Key words: malignant peripheral nerve sheath tumor, cell line, tissue culture, comparative genomic hybridization associated with neurofibromatosis 1 (NF1) (1). MPNST is highly progressive and resistant to radiation and chemotherapy, and therefore carries a poor prognosis $(2,3) ; 65 \%$ of patients develop distant metastases to the lung or bone (4), and 63-68\% of patients die of the disease $(1,4)$. The overall 5- and 10-year survival rates are $34-52 \%$ and $23-34 \%$, respectively $(1,5)$. The only existing effective therapy for MPNST is aggressive surgery with wide surgical margins $(3,5)$. Basic research to develop new treatment regimes is critically needed. Cell lines for the disease provide useful tools to investigate the mechanisms involved in the aggressive malignant behavior of MPNSTs and to examine responses to therapy (6-8). Six MPNST cell lines have been reported to date, but none of these are commercially available (9-13). Here we describe three new MPNST cell lines, designated as FU-SFT8611, FU-SFT8710 and FU-SFT9817, together with their immunocytochemical profiles, G-band karyotypes and genomic imbalances demonstrated by comparative genomic hybridization $(\mathrm{CGH})$.

\section{Materials and methods}

Source of tumor cells. The FU-SFT8611 cells were obtained from a metastatic lesion of MPNST in a 40-year-old Japanese man. Nine years earlier, a neurofibroma was excised from the left chest wall of this patient. However, local recurrence was noted six years later. The recurrent tumor was excised and diagnosed as MPNST, but another metastatic lesion appeared in the left axilla. The cell line was prepared from the recurrent axillary tumor, which was histopathologically consistent with MPNST (Fig. 1a).

The origin of the FU-SFT8710 cells was a 43-year-old Japanese woman who was clinically diagnosed with von Recklinghausen's disease. Three years earlier, a right buttock tumor had been resected and diagnosed as neurofibroma. The tumor recurred on the same region in connection with the ischiadic nerve. Histologic examination showed MPNST (Fig. 1b).

The FU-SFT9817 cultured cells were derived from a tumor on the right thigh in a 61-year-old Japanese woman. The tumor had appeared three years earlier, and grown progressively thereafter. The histopathological features of the surgically resected tumor were consistent with MPNST (Fig. 1c). 

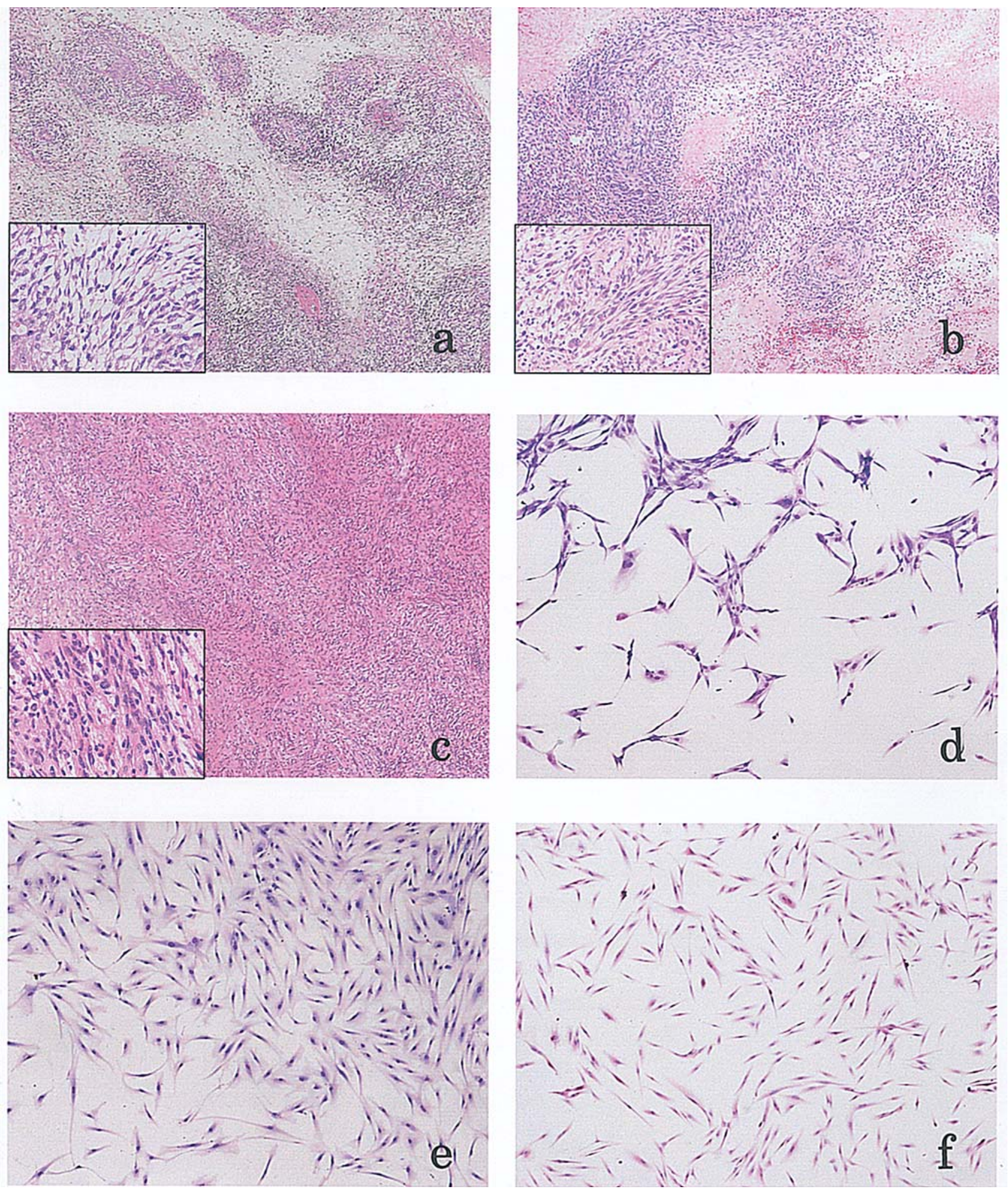

Figure 1. Light microscopy of original tumors (a-c) and cell lines in vitro (d-f). (a) FU-SFT8611 original tumor; (b) FU-SFT8710 original tumor; (c)FU-SFT9817 original tumor; (d) FU-SFT8611 cell line; (e) FU-SFT8710 cell line; (f) FU-SFT9817 cell line. (a-c, f) H\&E; (d, e) Giemsa. Original magnification: a-c, x40; inset, $\mathrm{x} 200 ; \mathrm{d}-\mathrm{f}, \mathrm{x} 100$.

Histological diagnosis of MPNST was based on the widely accepted criteria that require the tumor to conform to one of the following: i) arises within a peripheral nerve; ii) arises in transition from a benign or other malignant peripheral nerve tumor; iii) develops in a patient with NF1 (von Recklinghausen's disease) and exhibits the same histological features as do the majority of MPNSTs arising from nerves; or iv) develops in a patient without NF1, but exhibits the same histological features as do most MPNSTs and shows either or both immunohistochemical and ultrastructural features of Schwann or perineural cell differentiation (14).

Cell culture. Following surgical resection, minced fragments of tumor tissues were digested with $400 \mathrm{U} / \mathrm{ml}$ type II collagenase 
Table I. Antibodies used in the present study.

\begin{tabular}{lclc}
\hline Antibody & Type & \multicolumn{1}{c}{ Source } & Dilution \\
\hline S-100 & $\mathrm{P}$ & Dakopatts, Kyoto, Japan & \\
1:1000 & & & \\
NSE & $\mathrm{M}$ & Dakopatts & $1: 200$ \\
Vimentin & $\mathrm{M}$ & Dakopatts & $1: 100$ \\
a-SMA & $\mathrm{P}$ & Dakopatts & $1: 50$ \\
EMA & $\mathrm{M}$ & Dakopatts & $1: 100$ \\
AE1/AE3 & $\mathrm{P}$ & Dakopatts & $1: 400$ \\
C-kit & $\mathrm{P}$ & Immuno-Biological Laboratories, & $1: 10$ \\
& & Fujioka, Japan & $1: 50$ \\
CD57 & $\mathrm{M}$ & Becton Dickinson, San Jose, CA & \\
(Leu-7) & & & $1: 40$ \\
$\begin{array}{l}\text { CD34 } \\
\text { (My10) }\end{array}$ & $\mathrm{M}$ & Beckton Dickinson & \\
\hline
\end{tabular}

NSE, neuron specific enolase; $\alpha$-SMA, $\alpha$-smooth muscle actin; EMA, epithelial membrane antigen; $\mathrm{P}$, polyclonal (rabbit); M, monoclonal (mouse).

(Worthington Biochemical Corporation, Freehold, NJ) in culture medium for $30 \mathrm{~min}$ at $37^{\circ} \mathrm{C}$. The tumor cells were then washed, resuspended in culture medium in plastic flasks (Falcon Primaria, Becton Dickinson Japan, Tokyo, Japan), and incubated in a humidified atmosphere of $5 \% \mathrm{CO}_{2}$ in air at $37^{\circ} \mathrm{C}$. The culture medium was composed of a $1: 1$ mixture of Dulbecco's modified Eagle's medium (DMEM) and Ham's F12 (Gibco BRL, Paisley, UK) supplemented with 10-20\% fetal calf serum (HyClone Laboratories, Logan, UT) and kanamycin sulfate (100 $\mu \mathrm{g} / 1$, Meiji Seika, Tokyo). The medium was replaced twice a week. Four weeks later, semiconfluent layers were subcultured for the first time using $0.02 \%$ EDTA and $0.1 \%$ trypsin.

Growth kinetics. Growth curves of FU-SFT8611, FU-SFT8710 and FU-SFT9817 cells were estimated at passage 79, 78 and 140 , respectively. The cells were seeded in 24-well culture plates (Corning, New York, NY) at $8 \times 10^{3}$ cells per well, containing $1 \mathrm{ml}$ culture medium, and then harvested every day thereafter for 10 days, followed by counting the number of viable cells by dye exclusion [0.3\% trypan blue in phosphatebuffered saline (PBS)].

Tumorigenicity in nude mice. To determine the tumorigenicity of FU-SFT8611, FU-SFT8710 and FU-SFT9817 cells in vivo, $1 \times 10^{7}$ cells at passage 10,28 and 41 , respectively, were washed, suspended in PBS, and injected subcutaneously into the backs of congenitally athymic nude mice (BALB/c nu/nu, Jcl Clea Japan Inc., Osaka, Japan) or athymic SCID mice (CB-17/Icr-scid, Jcl Clea Japan). The mice were maintained in a pathogen-free environment and carefully observed until tumors grew to at least $1.5 \mathrm{~cm}$ in size at the largest dimension. The experimental protocol was approved by the Ethics Review
Committee for Animal Experimentation of Fukuoka University School of Medicine.

Pathological evaluation. For routine light microscopy, original tumors and xenografts were formalin-fixed and embedded in paraffin. Serial $3-\mu \mathrm{m}$ sections were prepared on glass. The cells cultured in chamber slides (Lab-Tek, Miles Laboratories, Naperville, IL) were washed in PBS and fixed in methanol for $5 \mathrm{~min}$. The slides were stained with hematoxylin and eosin (H\&E) and Giemsa. Table I lists the primary antibodies and their dilutions used for immunocytochemistry. The cells were reacted with each of the primary antibodies for $1 \mathrm{~h}$ at room temperature. The bound antibodies were then visualized using a labeled streptavidin-biotin system and an alkaline phosphatase technique. Paraffin sections from original tumors and xenografts were also examined using the same procedure.

Cytogenetic analysis. MPNST cell lines at passage 20-22 were used for cytogenetic analysis. Metaphase preparations were made using the standard trypsin-Giemsa banding technique as described previously (15). Chromosomes were classified according to the 1995 International System for Human Cytogenetic Nomenclature (16) .

Comparative genomic hybridization. DNA was extracted from MPNST cell lines or original tumors according to the standard procedure using phenol and chloroform extraction followed by ethanol precipitation. The purity and molecular weight of DNA were estimated using ethidium bromide-stained agarose gels. CGH was performed as described previously (17). Briefly, tumor DNA was directly labeled with fluorescein-12-dUTP (Roche Diagnostics, Mannheim, Germany) by nick translation using a commercial kit (Vysis, Downers Grove, IL). As a normal reference DNA, Spectrum Red-labeled male total human DNA (Vysis) was used. Subsequently, equal amounts of labeled tumor and reference DNA (800 ng) and $20 \mu \mathrm{g}$ of Cot-1 DNA (Gibco BRL, Gaithersburg, MD) were coprecipitated with ethanol. The precipitated DNA was dissolved in $10 \mu 1$ of hybridization buffer $(50 \%$ formamide, $10 \%$ dextran sulfate, $2 \mathrm{X}$ standard saline citrate) and denatured at $75^{\circ} \mathrm{C}$ for $8 \mathrm{~min}$. Normal metaphase spreads (Vysis) were denatured for $3 \mathrm{~min}$ at $75^{\circ} \mathrm{C}$ and hybridized with the DNA mixture in a moist chamber for $72 \mathrm{~h}$. The slides were washed according to the protocol supplied by the manufacturer. After air drying, the slides were counterstained with 4,6-diamino-2-phenylindole (DAPI; Sigma, St. Louis, MO) and embedded in anti-fade solution (Vectashield, Vector Laboratories, Burlingame, CA).

Digital image analysis. The location of aberrant CGH signals was analyzed using an image analysis system (Isis, Carl Zeiss Vision, Oberkochen, Germany) based on an integrated highsensitivity monochrome charge-coupled device camera and automated CGH analysis software (MetaSystems, Altlussheim, Germany). Three-color images, green (fluorescein-12-dUTP) for the tumor DNA, red (Spectrum Red) for the reference DN, and blue (DAPI) for the DNA counterstain, were acquired at least 10 metaphases in each sample. Only metaphases of good quality with strong, uniform hybridization were included. Based on control experiments, 1.20 and 0.80 were used as cutoff levels for gains and losses, respectively. Gains exceeding 
Table II. Immunohistochemical profiles of each cell line and original tumor.

\begin{tabular}{|c|c|c|c|c|c|c|c|c|}
\hline \multirow[b]{2}{*}{ Antibody } & \multicolumn{3}{|c|}{ FU-SFT 8611} & \multicolumn{3}{|c|}{ FU-SFT 9817} & \multicolumn{2}{|c|}{ FU-SFT 8710} \\
\hline & In vitro & In vivo & Original tumor & In vitro & In vivo & Original tumor & In vitro & Original tumor \\
\hline S-100 & - & - & $t^{\mathrm{a}}$ & - & + & + & - & + \\
\hline NSE & + & + & + & - & + & + & $+^{a}$ & + \\
\hline Vimentin & + & + & + & + & + & + & + & + \\
\hline$\alpha-\mathrm{SMA}$ & - & - & - & - & - & - & - & - \\
\hline EMA & - & - & - & - & - & - & - & - \\
\hline AE1/AE3 & - & - & - & - & - & - & - & - \\
\hline C-KIT & - & - & - & - & - & - & - & - \\
\hline CD57 & $+^{\mathrm{a}}$ & - & $+^{\mathrm{a}}$ & - & - & - & - & $+^{\mathrm{a}}$ \\
\hline CD34 & - & - & - & - & - & - & - & - \\
\hline
\end{tabular}

-, negative; +, positive; afocally positive; in vitro, cultured tumor cells; in vivo, tumor cells grown in nude mice.

the 1.50 threshold were termed high-level amplifications. Hybridization of fluorescein-12-dUTP-labeled normal female DNA against Spectrum Red-labeled normal male DNA was used as a negative control, whereas MEP 600 DNA (Vysis) from a female breast cancer cell line, with known abnormalities including gain of 1q, loss of 9p, distal 11q deletion and loss of $16 \mathrm{q}$, was used as a positive control (18). The heterochromatic regions in chromosomes 1,9 and 16 , as well as the p-arms of the acrocentric chromosomes and $\mathrm{Y}$ chromosome were excluded from the analysis because of suppression of Cot-1 DNA hybridization in these regions.

\section{Results}

Establishment of FU-SFT8611, FU-SFT8710 and FU-SFT9817 cell lines. After establishment of the primary cell culture, all tumor cell lines grew consistently without contact inhibition. Four weeks after initial cultivation in the primary culture, polygonal or spindle-shaped tumor cells reached subconfluence. The cells were collected after 5 -min digestion at $37^{\circ} \mathrm{C}$ with a $0.1 \%$ trypsin solution and replated in two $25-\mathrm{cm}^{2}$ plastic flasks containing fresh medium. Thereafter, the cells were serially subcultured at a dilution of 1:2 when confluent. Approximately 2 months later, at passage 5 to 6, FU-SFT8611 and FUSFT9817 began to grow rapidly and thereafter were serially subcultured at a dilution of 1:4 every week. FU-SFT8710 cells were more slow-growing and were serially subcultured at a dilution of 1:2 every week.

Growth kinetics. The population-doubling time in logarithmic growth phase was approximately $50 \mathrm{~h}$ for FU-SFT8611, $68 \mathrm{~h}$ for FU-SFT8710 and $19 \mathrm{~h}$ for FU-SFT9817. These cell lines were maintained in vitro for more than 139, 88 and 234 passages, respectively.

Tumorigenicity in nude mice. FU-SFT8611 xenografts grew slowly, and small nodules on the back were first palpable 6 months after inoculation of the tumor cells. In contrast, FUSFT9817 xenografts grew fast and were palpable within 3 weeks after inoculation of the cultured cells. Round nodules continued to develop, growing to at least $1.5 \mathrm{~cm}$ in maximum diameter at the sites of injection by 15 weeks after inoculation. The cut surfaces of these tumors were solid and white with no secondary changes; the pathological and immunocytochemical features were similar to those of the original tumor (Table II). No metastatic lesions were identified at autopsy. Inoculation of FU-SFT8710 cells produced no tumor within 12 months after transplantation in nude and SCID mice.

Histopathological findings. Light microscopy analysis of the FU-SFT8611, FU-SFT8710 and FU-SFT9817 cells growing on chamber slides revealed spindle- or polygonal-shaped cells with extended thin processes and oval nuclei. These cells proliferated loosely as interconnected cords or networks or compactly in a sheet-like pattern, accompanied by irregularly piled-up foci (Fig. 1d-f).

Immunohistochemical findings. The immunohistochemical profiles are summarized in Table II. Most of the cells showed positive staining for vimentin and neuron specific enolase (NSE), but were negative for $\alpha$-smooth muscle actin ( $\alpha$-SMA), epithelial membrane antigen (EMA), cytokeratin AE1/AE3, c-KIT and CD34. CD57 was focally positive in FU-SFT8710 original tumor tissue, as well as in FU-SFT8611 original tumor and cultured cells. All original tumors expressed S-100 protein (Fig. 2a and d), but their cell lines did not. However, transplanted FU-SFT9817 and FU-SFT8611 cells expressed S-100 protein (Fig. 2b) and NSE (Fig. 2c), respectively. Either one or both of the corresponding transplanted and cultured cells therefore mirrored the immunoprofiles of the original tumors.

Cytogenetic analysis. Representative karyotypes are shown in Fig. 3. To assess the cell line karyotypes, we examined a total of 21, 34 and 14 metaphases of FU-SFT8611, FU-SFT8710 and FU-SFT9817 cell lines, respectively. All displayed complicated karyotypes with no common abnormalities. The composite karyotypes were as follows: 73-82, XXY, -Y, der(1)t(1;5)(p32;q13), $\operatorname{add}(2)(q 35), \operatorname{add}(2)(q 21)$, 


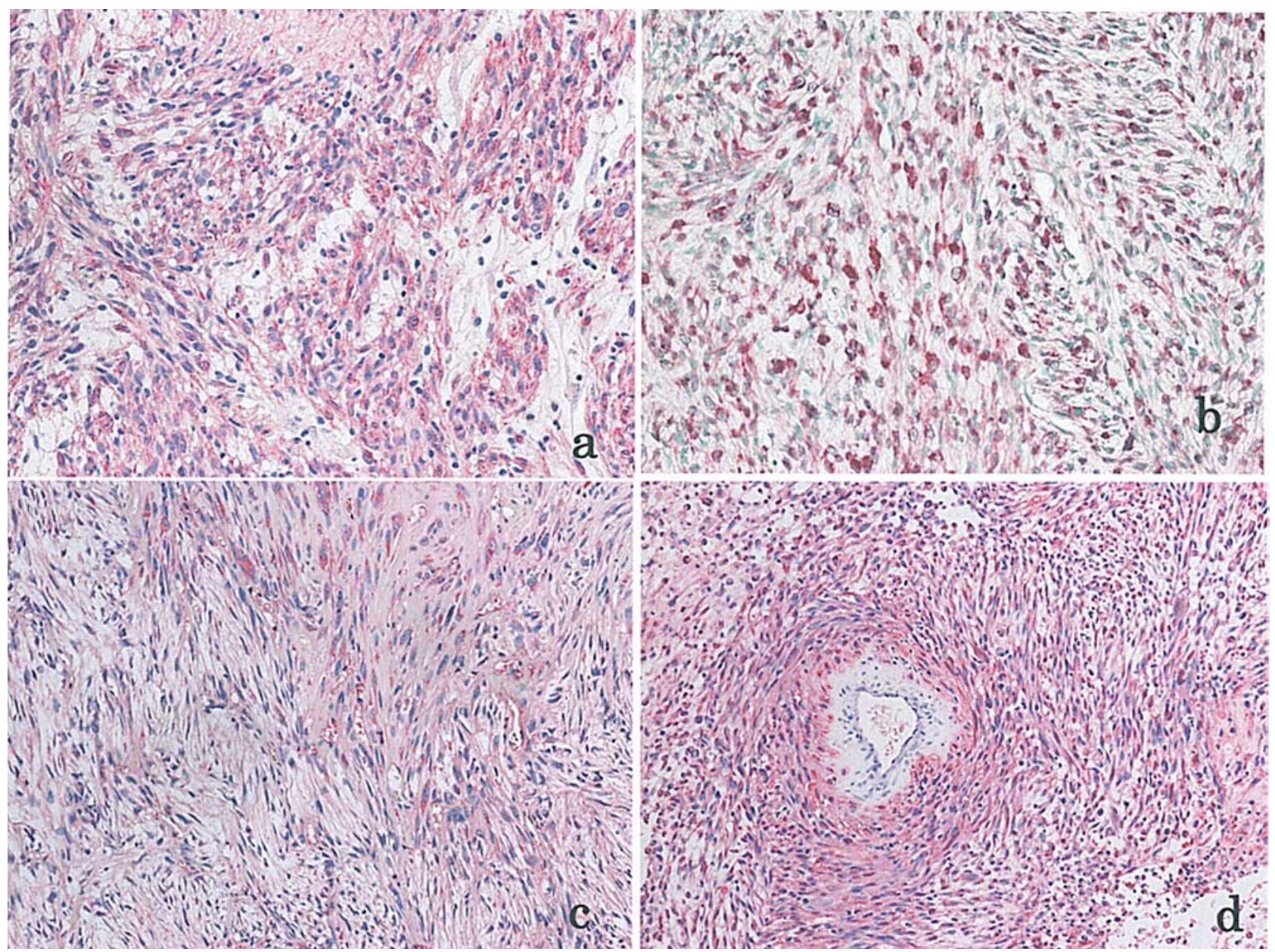

Figure 2. Immunohistochemistry of original tumors and xenografts. (a) SFT9817 original tumor showing diffuse positive staining for S-100 protein. (b) SFT9817 xenografts grown in nude mice stain positive for S-100 protein. (c) FU-SFT8611 xenografts show staining for NSE. (d) SFT8710 original tumor shows diffuse and strong positive reactivity to S-100 protein. Original magnification: $\mathrm{x} 200$.

$\operatorname{add}(3)(\mathrm{q} 21), \operatorname{add}(4)(\mathrm{q} 31), \operatorname{add}(5)(\mathrm{p} 15.3), \operatorname{del}(6)(\mathrm{q} 21)$, $+\operatorname{del}(6)(\mathrm{q} 21),+8,+9,+10, \operatorname{add}(11)(\mathrm{q} 21),-12,-14$ $\operatorname{add}(16)(\mathrm{p} 13),+\operatorname{add}(16)(\mathrm{q} 13),+\operatorname{add}(17)(\mathrm{q} 23),+18$, $\operatorname{der}(19) \mathrm{t}(2 ; 19)(\mathrm{q} 12 ; \mathrm{p} 13), \operatorname{der}(19) \mathrm{t}(2 ; 19)(\mathrm{q} 12 ; \mathrm{p} 13),+12$, $+21,-22,+\operatorname{der}(?) \mathrm{t}(5 ; ?)(\mathrm{q} 13 ; ?), \operatorname{der}(?) \mathrm{t}(18 ; ?)(\mathrm{q} 11 ; ?)$ [cp17] for FU-SFT8611; 72-76, XXX, +X, +2, add(3)(q29), +5, $-6,+7, \mathrm{i}(8)(\mathrm{q} 10), \operatorname{add}(9)(\mathrm{p} 22),+\operatorname{add}(9)(\mathrm{p} 22),-10$, $\operatorname{der}(10 ; 15) t(q 10 ; q 10),-11,+\operatorname{add}(12)(p 13),-13,-14,-15,-16$, $-16,+17,-18, \operatorname{dup}(18)(\mathrm{q} 23 \mathrm{q} 11)$, ins $(19 ; 14)(\mathrm{p} 13 ; \mathrm{q} 31 \mathrm{q} 11)$, + ins $(19 ; 14)(\mathrm{p} 13 ; \mathrm{q} 31 \mathrm{q} 11),+20,+20, \operatorname{der}(22) \mathrm{t}(9: 22)(\mathrm{q} 10: \mathrm{p} 12)$, $+\operatorname{der}(22) \mathrm{t}(9 ; 22)(\mathrm{q} 10 ; \mathrm{p} 12),+\operatorname{der}(?) \mathrm{t}(21 ; ?)(\mathrm{q} 11: ?) \mathrm{x} 2$, +4-6mar [cp27] for FU-SFT8710; and 59-58, XX, $\operatorname{der}(1 ; 2)(1 \mathrm{qter} \rightarrow 1 \mathrm{p} 36:: 12 \mathrm{q} 11 \rightarrow 12 \mathrm{qter}),+\operatorname{dup}(2)(\mathrm{q} 21 \mathrm{q} 31)$, $3+4+\mathrm{i}(5)(\mathrm{q} 10),+6,+\mathrm{i}(7)(\mathrm{q} 10), \operatorname{der}(8)(8 ; 8)(\mathrm{q} 24 ; \mathrm{q} 24),+12,-13$, $-13, \operatorname{der}(15) \mathrm{t}(15 ; 17)(\mathrm{p} 11 ; \mathrm{q} 11),+16,-17,-17,+18,+20,+21$, $+22,+3 \sim 8 \operatorname{mar}$ [cp7] for FU-SFT9817.

CGH. CGH analysis revealed similar profiles between original tumors and their corresponding cell lines. However, no common significant losses or gains of DNA sequences or high-level amplification were apparent among the cell lines (Fig. 4a-c). Chromosomal imbalances in the three cell lines analyzed by $\mathrm{CGH}$ were as follows: gain 7 loss 4 (Imbalances 11), -1q24-q31, +5p15.3-pter, +8q11.2-qter, +12q24-qter, -15p11.2-q21.3, +16p13.1-pter, +17q22-qter, +20q12-qter, +21q11.1-qter, -Xp11.2-p22.1, -Yq11.1-qter for FU-SFT8611; gain 10 loss 12 (Imbalances 22) , +4q31.3-qter, +5q11.1-q11.2, -6p21.1-pter, -6q13-q16.1, +7q11.22-q11.23, +8q24.3-qter, +9cen-q21.2, -10pter-q22.3, -11p15.4-p11.12, -11q22.1-qter, +12pter-q12, -13p11.2-q21.3, -14q21-qter, -16q11.2-q22, +17q25-qter, -18p11.31-q11.2, -18q12.1-q21.1, +19cen-q13.1, +20cen-q11.2, +Xter-p22.2, +Xcen-q13, -Y11.23-qter for FU-SFT8710; and gain 20 loss 16 (Imbalances 36), -1p34.1qter, +1p31.2-q21.3, +2cen-p14, +2q22-q24.3, +2q33-q35, $+3 \mathrm{p} 13-\mathrm{q} 21.1,-4 \mathrm{p} 16.1$-pter, $+4 \mathrm{p} 14-\mathrm{q} 13.3,+5 \mathrm{p} 13.2-\mathrm{q} 13.1$, $+5 \mathrm{q} 13.3-\mathrm{q} 23.3,+6 \mathrm{p} 12-\mathrm{q} 23.3,+7$ cen-q11.23, +7q31.1-q31.3, -8p21.3-pter, +8q13-q23, -9q23-qter, +9p13-q21.2, +10p11.2-q21.1, -11q23.3-qter, -12q24.1-qter, +12p12.1-q13.1, -13q32-qter, -14q24.3-qter, -15q21.2-qter, -16p12-pter, +16p11.2-q11.2, -17q22-qter, +18p11.2-q11.2, -19p13.2-pter, -19q13.2-qter, +20p11.2-q12, -21q22.1-qter, -22q12.3-q13.2, -Xq26.3-q28, +Xp11.21-q21.1, +Ypter-qter for FU-SFT9817.

\section{Discussion}

In the present study, we established three new MPNST cell lines, denoted FU-SFT8611, FU-SFT8710 and FU-SFT9817. The three tumors from which these cell lines were respectively 


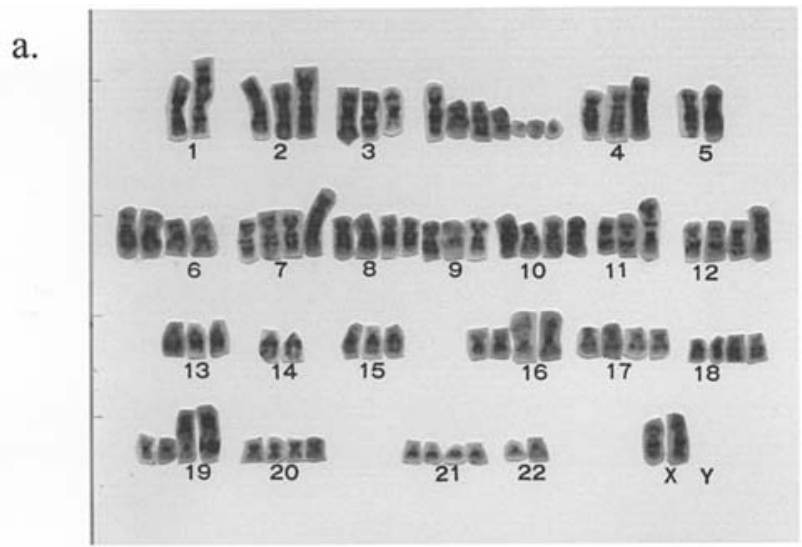

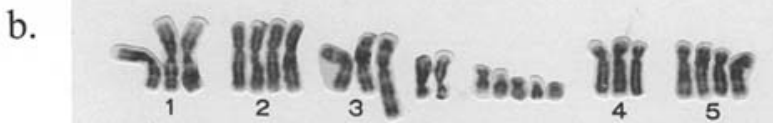

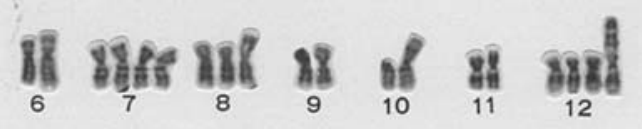

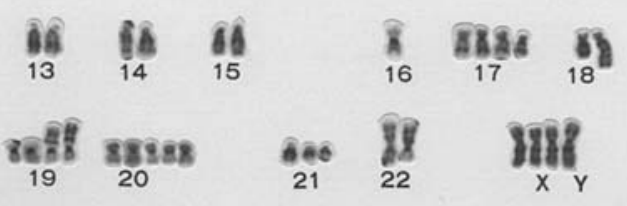

c.
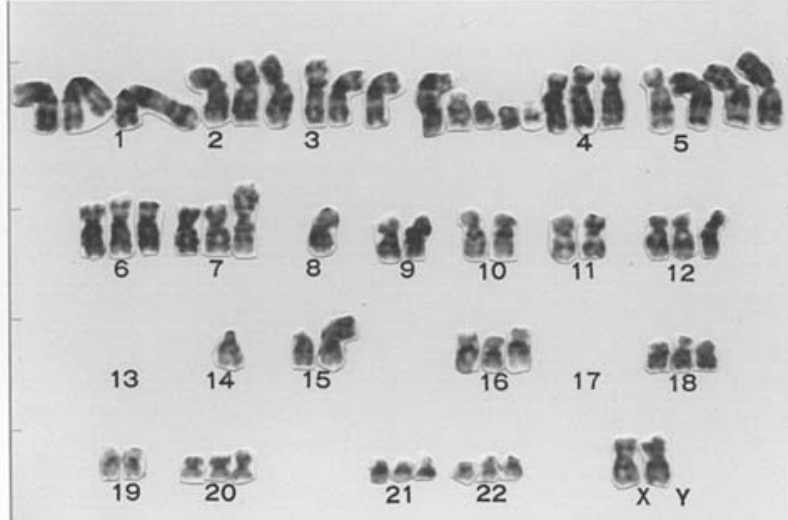

Figure 3. Representative G-band karyotypes of cell lines. (a) FU-SFT8611; (b) FU-SFT8710; (c) FU-SFT9817.

derived were diagnosed as MPNST based on histopathological and immunohistochemical findings. One was NF1-associated and the other two were sporadic MPNST. The three cell lines retained characteristics of their original tumors histologically, immunohistochemically and also chromosomally. Moreover, two of the three lines (FU-SFT8611 and FU-SFT9817) were tumorigenic in nude mice.

Few reports describing the establishment of human MPNST cell lines have been published to our knowledge, and no MPNST cell lines are commercially available. HKMS was the first such cell line reported, established from an ordinarytype MPNST in a 48-year-old woman without NF1 (9). YST-1 was established from an epithelioid malignant Schwannoma in an 8-year-old girl without NF1 (10). ST88-14 was derived from an ordinary-type MPNST in a 30-year-old man with a.

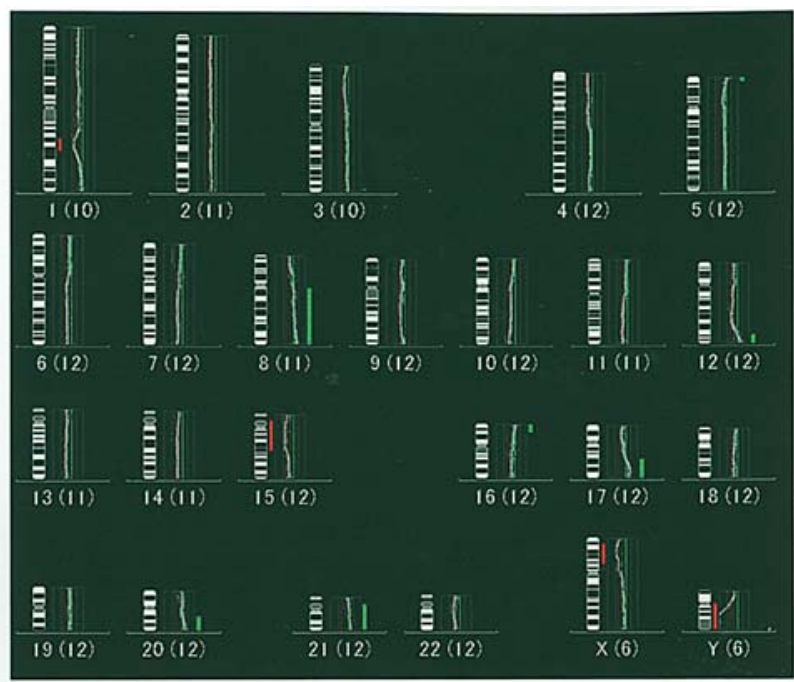

b.

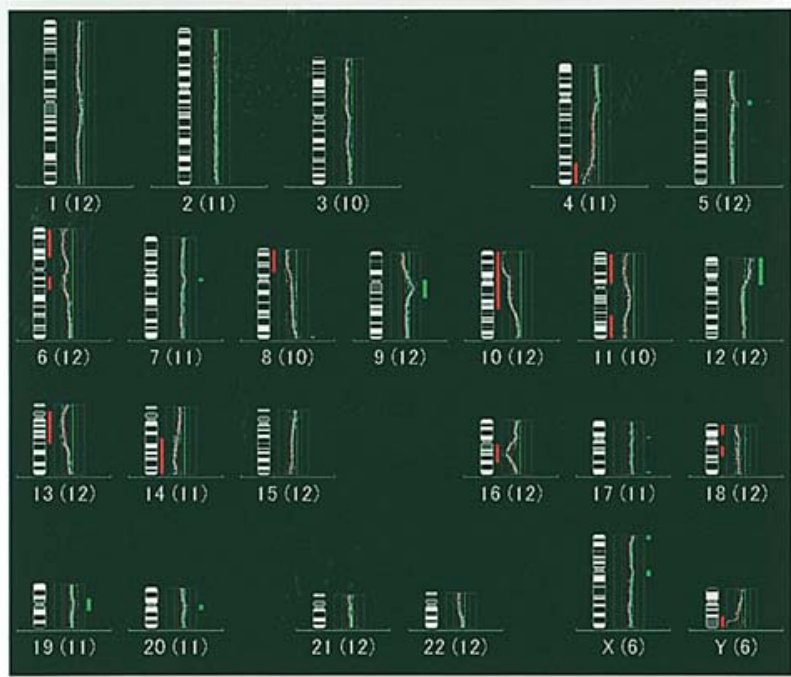

c.

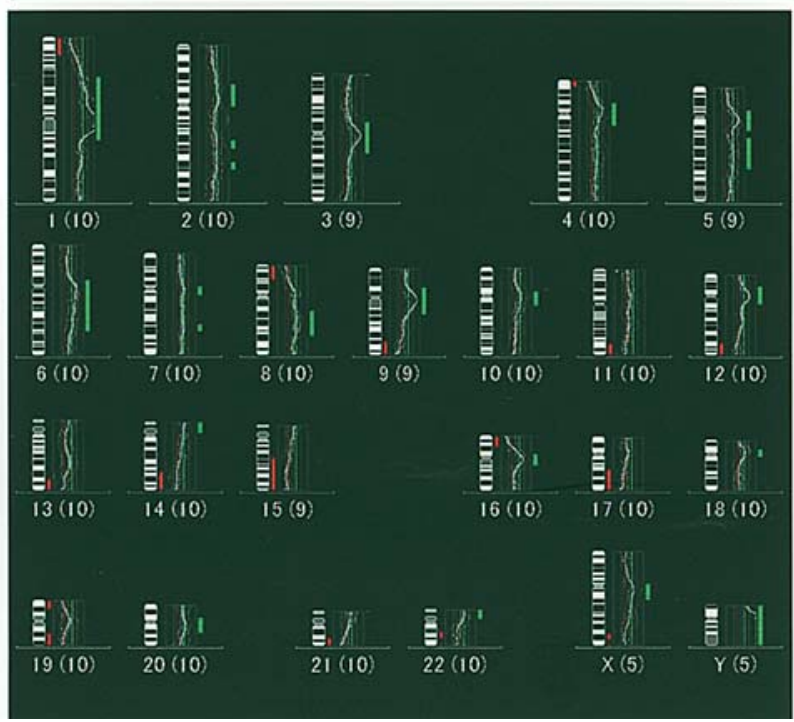

Figure 4. CGH profiles of original tumors. (a) FU-SFT8611; (b) FU-SFT8710; (c) FU-SFT 9817.

NF1, and showed a complex hyperdiploid karyotype with 17q11.2 translocation (11). NMS-2 and NMS-2PC were both established from an ordinary-type MPNST in a 30-year-old man with NF1; NMS-2 originated from the primary tumor, and NMS-2PC was derived from a metastatic tumor (12). 
Both NMS-2 and NMS-2PC showed complex karyotypic abnormalities, including some on chromosome 17. HS-Sch-2 was established from an ordinary-type MPNST in a 54-yearold man without NF1, and exhibited a hypotriploid karyotype with complex chromosome abnormalities lacking a specific pattern, as well as a p53 point mutation (13). All six previously reported cell lines were tumorigenic in nude mice.

FU-SFT8611, FU-SFT9817 and FU-SFT8710 cells grown in culture and xenografts of FU-SFT8611and FU-SFT9817 transplanted into nude mice showed immunohistochemical profiles similar to those of the respective original tumors, except for the expression of S-100 protein. All three original tumors expressed S-100 protein, while the corresponding cell lines grown in culture were S-100-negative. However, only $50-70 \%$ of MPNSTs in vivo express S-100 protein heterogeneously and sporadically $(19,20)$. Four of the six previously published MPSNT cell lines demonstrated reactivity to S-100 protein (9-13). Moreover, FU-SFT9817 cells expressed both S-100 protein and NSE when transplanted into nude mice, and FU-SFT8611 xenografts also expressed NSE. These findings suggest that interactions between tumor cells and stromal cells facilitate the expression of these peripheral nerve-associated marker proteins. In any case, our study shows that these cell lines retain the potential to express peripheral nerve-associated proteins.

Highly complex and aberrant karyotypes containing numerical and structural changes have been described for NF-1-associated and sporadic MPNSTs, and no cytogenetic differences have been found between them (21-23). Jhanwar et al (22) described recurrent abnormalities (numerical as well as structural) of chromosomes 1, 11, 12, 14, 17 and 22 in a substantial proportion of 10 tumors, nine of which were NF1associated. Six tumors had abnormalities of both chromosomes 17 and 20. In contrast, Mertens et al (21) found no recurrent structural rearrangements in their 8 MPNSTs. Combining their data with those from 20 previously published MPNST samples revealed that the most frequently rearranged bands were $7 \mathrm{p} 22$ in 6 tumors, as well as 1p21,7p11 and 14q11 in 5 tumors each. Most numerical and unbalanced structural aberrations led to loss of genetic material, especially from Xq26-qter (13 tumors); 11q22-qter and 13p (12 tumors); 9p22-pter, 11p13-pter, 17p and 17q11-21 (11 tumors); and, 1p22-32 and 1p34-pter (10 tumors). Schmidt et al (23) also found no recurrent pattern in the structural changes observed between six MPNSTs from four different patients. Most of the structural and numerical chromosomal aberrations were detected in chromosomes 1 , 5, 7-10, 14-17, 19, 21 and 22. We also found no consistent abnormalities in the three MPNSTs studied here, with abnormalities covering a wide range. Nevertheless, the chromosomes that frequently carried aberrations included 17 (5 times), 12 and 22 (4 times each), as well as 8 and 9 (3 times each); this is consistent with previous reports.

CGH studies have shown that chromosomal gains are more frequent than losses in both NF-1 associated and sporadic MPNST (24-26), and demonstrated some differences in the frequency and distribution of chromosomal imbalances between these MPNST types. For example, NF1-associated MPNST most frequently showed gains of 17q24 (24-27). Schmidt et al (26) analyzed 31 MPNST from 23 patients and found that gains of both 7p15-p21 and 17q22-qter were associated with a statistically significant poor survival rate. In our study, FU-SFT8710 was NF1-associated, while FU-SFT8611 and FU-SFT9817 were sporadic. All three cell lines showed many imbalances (range 11-36); FU-SFT 8710 and 9817 exhibited more frequent gains than losses, whereas FU-SFT 8611 showed more frequent losses. The cell lines showed no consistent aberrations, although the cell-line aberrations were closely similar to those of their original tumors, indicating that the cell lines retain the genetic characteristics of their original tumors. As for chromosomal imbalances related to poor survival, FU-SFT8611 exhibited gain of 17q22-qter, and FUSFT9817 exhibited loss of 17q22-qter. Gains of 17q24 and 7 p15-p21 were not detected in any of the cell lines.

In conclusion, we described characteristics of FU-SFT8611, FU-SFT8710 and FU-SFT9817, three new MPNST-derived cell lines. MPNST remains a fatal malignancy for which no effective cure is available. The three cell lines established in this work may be useful tools for various biological investigations and to develop new therapies for MPNST.

\section{References}

1. Ducatman BS, Scheithauer BW, Piepgras DG, Reiman HM and Ilstrup DM: Malignant peripheral nerve sheath tumors. A clinicopathologic study of 120 cases. Cancer 57: 2006-2021, 1986.

2. Kourea HP, Bilsky MH, Leung DH, Lewis JJ and Woodruff JM: Subdiaphragmatic and intrathoracic paraspinal malignant peripheral nerve sheath tumors: a clinicopathologic study of 25 patients and 26 tumors. Cancer 82: 2191-2203, 1998.

3. Wanebo JE, Malik JM, VandenBerg SR, Wanebo HJ, Driesen N and Persing JA: Malignant peripheral nerve sheath tumors. A clinicopathologic study of 28 cases. Cancer 71: 1247-1253, 1993.

4. Hruban RH, Shiu MH, Senie RT and Woodruff JM: Malignant peripheral nerve sheath tumors of the buttock and lower extremity. A study of 43 cases. Cancer 66: 1253-1265, 1990.

5. Wong WW, Hirose T, Scheithauer BW, Schild SE and Gunderson LL: Malignant peripheral nerve sheath tumor: analysis of treatment outcome. Int J Radiat Oncol Biol Phys 42: 351-360, 1998.

6. Dang I and DeVries GH: Schwann cell lines derived from malignant peripheral nerve sheath tumors respond abnormally to platelet-derived growth factor-BB. J Neurosci Res 79: 318-328, 2005.

7. Su W, Gutmann DH, Perry A, Abounader R, Laterra J and Sherman LS: CD44-independent hepatocyte growth factor/c-Met autocrine loop promotes malignant peripheral nerve sheath tumor cell invasion in vitro. Glia 45: 297-306, 2004.

8. DeClue JE, Heffelfinger S, Benvenuto G, Ling B, Li S, Rui W, Vass WC, Viskochil D and Ratner N: Epidermal growth factor receptor expression in neurofibromatosis type 1-related tumors and NF1 animal models. J Clin Invest 105: 1233-1241, 2000.

9. Ono I, Ishiwata I, Nakaguchi T, Soma M, Tokita N, Ishiwata C, Mukai M, Nozawa S and Ishikawa H: Establishment and characterization of a human malignant Schwannoma cell line (HKMS). Hum Cell 2: 272-277, 1989.

10. Nagashima Y, Ohaki Y, Tanaka Y, Sumino K, Funabiki T, Okuyama T, Watanabe S, Umeda M and Misugi K: Establishment of an epithelioid malignant Schwannoma cell line (YST-1). Virchows Arch B Cell Pathol Incl Mol Pathol 59: 321-327, 1990.

11. Reynolds JE, Fletcher JA, Lytle CH, Nie L, Morton CC and Diehl SR: Molecular characterization of a 17q11.2 translocation in a malignant Schwannoma cell line. Hum Genet 90: 450-456, 1992.

12. Imaizumi S, Motoyama T, Ogose A, Hotta T and Takahashi HE: Characterization and chemosensitivity of two human malignant peripheral nerve sheath tumour cell lines derived from a patient with neurofibromatosis type 1. Virchows Arch 433: 435-441, 1998.

13. Sonobe H, Takeuchi T, Furihata M, Taguchi T, Kawai A, Ohjimi Y, Iwasaki H, Kaneko Y and Ohtsuki Y: A new human malignant peripheral nerve sheath tumour-cell line, HS-sch-2, harbouring p53 point mutation. Int J Oncol 17: 347-352, 2000. 
14. Scheithauer BW, Woodruff JM: Malignant peripheral nerve sheath tumor (MPNST). In: Atlas of Tumor Pathology. Erlandson RA (ed). Third series. Armed Forces Institute of Pathology, Washington, DC, pp303-328, 1999.

15. Ohjimi Y, Iwasaki H, Kaneko Y, Ishiguro M, Ohgami A, Fujita C, Shinohara N, Yoshitake K and Kikuchi M: Chromosome abnormalities in liposarcomas. Cancer Genet Cytogenet 64: 111-117, 1992.

16. An International System for Human Cytogenetic NomenClature. S. Karger, Basel, 1995.

17. Nishio JN, Iwasaki H, Ohjimi Y, Ishiguro M, Koga T, Isayama T, Naito M and Kikuchi M: Gain of Xq detected by comparative genomic hybridization in elastofibroma. Int J Mol Med 10: 277-280, 2002.

18. Ohshima K, Ishiguro M, Ohgami A, Sugihara M, Haraoka S, Suzumiya J and Kikuchi M: Genetic analysis of sorted Hodgkin and Reed-Sternberg cells using comparative genomic hybridization. Int J Cancer 82: 250-255, 1999.

19. Weiss SW, Langloss JM and Enzinger FM: Value of S-100 protein in the diagnosis of soft tissue tumors with particular reference to benign and malignant Schwann cell tumors. Lab Invest 49: 299-308, 1983.

20. Matsunou H, Shimoda T, Kakimoto S, Yamashita H, Ishikawa E and Mukai M: Histopathologic and immunohistochemical study of malignant tumors of peripheral nerve sheath (malignant Schwannoma). Cancer 56: 2269-2279, 1985.

21. Mertens F, Rydholm A, Bauer HF, Limon J, Nedoszytko B, Szadowska A, Willen H, Heim S, Mitelman F and Mandahl N: Cytogenetic findings in malignant peripheral nerve sheath tumors. Int J Cancer 61: 793-798, 1995.
22. Jhanwar SC, Chen Q, Li FP, Brennan MF and Woodruff JM Cytogenetic analysis of soft tissue sarcomas. Recurrent chromosome abnormalities in malignant peripheral nerve sheath tumors (MPNST). Cancer Genet Cytogenet 78: 138-144, 1994.

23. Schmidt H, Taubert H, Wurl P, Bache M, Bartel F, Holzhausen HJ and Hinze R: Cytogenetic characterization of six malignant peripheral nerve sheath tumors: comparison of karyotyping and comparative genomic hybridization. Cancer Genet Cytogenet 128: $14-23,2001$

24. Koga T, Iwasaki H, Ishiguro M, Matsuzaki A and Kikuchi M: Frequent genomic imbalances in chromosomes 17, 19, and 22q in peripheral nerve sheath tumours detected by comparative genomic hybridization analysis. J Pathol 197: 98-107, 2002.

25. Mechtersheimer G, Otano-Joos M, Ohl S, Benner A, Lehnert T, Willeke F, Moller P, Otto HF, Lichter P and Joos S: Analysis of chromosomal imbalances in sporadic and NF1-associated peripheral nerve sheath tumors by comparative genomic hybridization. Genes Chromosomes Cancer 25: 362-369, 1999.

26. Schmidt H, Wurl P, Taubert H, Meye A, Bache M, Holzhausen HJ and Hinze R: Genomic imbalances of $7 p$ and $17 q$ in malignant peripheral nerve sheath tumors are clinically relevant. Genes Chromosomes Cancer 25: 205-211, 1999.

27. Lothe RA, Karhu R, Mandahl N, Mertens F, Saeter G, Heim S, Borresen-Dale AL and Kallioniemi OP: Gain of 17q24-qter detected by comparative genomic hybridization in malignant tumors from patients with von Recklinghausen's neurofibromatosis. Cancer Res 56: 4778-4781, 1996. 